\title{
El derecho a la libre autodeterminación de los pueblos y el caso fallido del Sahara Occidental. Los límites del cosmopolitismo y la ecosoberanía como propuesta alternativa
}

\section{The Self-Determination Right and the Failed Case of Western Sahara. The Limits of Cosmopolitism and the Ecosovereignity Alternative}

\author{
Myrna Rodríguez Añuez ${ }^{1}$ \\ Benemérita Universidad Autónoma de Puebla (México)
}

Recibido: 17-02-17

Aprobado: 20-03-17

\section{Resumen}

El conflicto del Sahara Occidental es un caso pendiente de descolonización en el continente africano. No obstante, su resolución sigue siendo compleja y difusa. Analizamos el caso a la luz del fracaso del cosmopolitismo y proponemos una lectura nueva de la búsqueda de la independencia del Sahara Occidental a partir del concepto de ecosoberanía, por considerarlo un intento teórico de actualizar el derecho a la libre autodeterminación en las condiciones internacionales del siglo XXI.

Palabras-clave: Autodeterminación, Soberanía, Ecosoberanía, Cosmopolitismo, Sahara Occidental.

\footnotetext{
${ }^{1}$ (mracubana@yahoo.com.mx) Es profesora-investigadora de la licenciatura en Relaciones Internacionales de la Benemérita Universidad Autónoma de Puebla y miembro del Cuerpo Académico "Política Exterior y Cooperación Internacional". Es autora del libro Breve historia de Ruanda y Burundi. De la época precolonial hasta los años noventa (BUAP/Juan Pablos Editores, 2013) y coeditora del libro Los BRICS y el discurso del nacionalismo en el siglo XXI (Washington, Westphalia Press, 2015). Es Historiadora egresada de la Universidad de La Habana; obtuvo su maestría en Estudios de Asia y África con especialidad en África por El Colegio de México y es candidata a doctora en Relaciones Internacionales por la UNAM.
} 


\begin{abstract}
Western Sahara is still a territory waiting for the end of the decolonization process in Africa. Its institutional solution is complex and shows the failure of cosmopolitan perspectives to explain it. The analysis in this article introduces and proposes a new theoretical lecture of the conflict, under the concept of ecosovereignty to adequate self-determination in the framework of Twenty Firs Century international relations.
\end{abstract}

Key-words: Self-determination, Sovereignty, Ecosovereignty, Cosmopolitanism, Western Sahara.

Ellos se llaman hijos de las nubes, porque desde siempre persiguen la lluvia. Desde hace más de treinta años persiguen, también, la justicia, que en el mundo de nuestro tiempo parece más esquiva que el agua en el desierto.

Eduardo Galeano, 2006.

\title{
Introducción
}

Los planteamientos cosmopolitas de la política internacional enfrentan desafíos importantes, particularmente cuando el sistema contemporáneo no ha resuelto añejos problemas de soberanía e independencia heredados del siglo XXI. En términos generales se pueden plantear las siguientes preguntas: ¿Es posible hablar de globalización, sociedad internacional, gobernanza global o cosmopolitismo en una era en la que el problema de la descolonización todavía no se ha resuelto? ¿Es eficaz seguir pensando el acceso a la soberanía de pueblos que han visto incumplida esa promesa desde el siglo XX, en un período histórico que parece cuestionar la legitimidad del derecho a la libre autodeterminación de los pueblos en su versión clásica? ¿Es posible pensar en el derecho a la libre autodeterminación de los pueblos a la luz de la legitimidad cosmopolita? ¿Han tenido éxito los reclamos soberanistas y del derecho a la libre autodeterminación de los pueblos desde una perspectiva cosmopolita coherente con la noción de gobernanza global? Todas estas preguntas guían el contenido del artículo que, mediante el análisis del caso de Sahara Occidental, cuestiona el ideal cosmopolita a la luz de su fracaso. 
El Sahara Occidental ${ }^{2}$ es uno de los países africanos pendiente de descolonización, y considerado por Naciones Unidas como un territorio no autónomo. Marcado por la administración colonial española, la lucha por la reivindicación de la independencia del pueblo saharaui se inició en 1975 cuando España transfirió la administración del Sáhara Occidental a Marruecos y Mauritania. Desde este momento empezaron los enfrentamientos donde el Frente Popular - conocido como Frente Polisario-creado en 1973, representaba el movimiento de independencia y el brazo político armado. Fruto de esta lucha por la independencia se establece el Estado Saharaui con la creación de la República Árabe Saharaui Democrática (RASD) en $1976^{3}$, el representante legítimo del pueblo saharaui.

En 1979, Mauritania abandona la contienda bélica y desde entonces el conflicto quedó entre Marruecos y el Frente Polisario hasta que en 1991 se firmó el alto al fuego. A partir de este momento, el Sahara Occidental se encuentra dividido territorialmente en dos partes - por un muro construido por el Gobierno marroquí ${ }^{4}$ - que delimita la parte oeste controlada por Marruecos que representa casi el $80 \%$ del territorio saharaui y la parte este $-20 \%$ de territorio desértico al interior - controlada por el Frente Polisario y la RASD -los llamados territorios liberados-. Como consecuencia del conflicto, a partir de 1976 se produjo un importante éxodo de la población saharaui hacia el Suroeste de Argelia donde viven alrededor de 120.000 saharauis instalados en campamentos de refugiados. Así, la población saharaui quedó separada entre la zona ocupada por Marruecos, la zona liberada y los campamentos de refugiados en Tindouf, Argelia 5 .

\footnotetext{
${ }^{2}$ Es un territorio de $280.000 \mathrm{~km} 2$, con grandes recursos en fosfatos y petróleo, con una costa de $1,000 \mathrm{~km}$ con grandes recursos pesqueros y una posición geográfica privilegiada al Atlántico. Las riquezas naturales sustentan el proyecto expansionista de ocupación de Marruecos sobre el territorio.

${ }^{3}$ La RASD es un gobierno efectivo en el exilio, consta de un entramado jurídico que controla y administra el territorio liberado - al este del muro-y a los que viven en los campamentos de refugiados. Consta de un poder ejecutivo formado por un gabinete dirigido por el primer ministro, un poder legislativo y un presidente que ocupa a la vez el cargo de Secretario General del Frente Polisario. Es reconocido por más de 80 estados -aunque las principales potencias, entre ellas las occidentales, se han abstenido de reconocerla según por considerar que pueden obstaculizar una solución negociaday es miembro de la Unión Africana desde 1982. El pasado mes de mayo de 2016 murió el histórico líder del Movimiento Nacional del Frente Polisario y Presidente de la RASD, Mohamed Abdelaziz. El nuevo Secretario General y Presidente es Brahim Gali; cargo que ejerce desde julio de 2016 donde fue elegido en un congreso extraordinario.

4 El llamado "Muro de la Vergüenza" fue construido entre 1980 y 1987 con financiación saudí con el propósito de frenar los ataques del Frente Polisario contra el ejército marroquí con la técnica de guerra de guerrillas. El muro construido por Marruecos es una muralla de $2.200 \mathrm{~km}$ de largo y 300 metros de ancho bordeado por un extenso campo minado y una dotación de 120.000 soldados marroquíes.

${ }^{5}$ Habría que añadir a saharauis que viven en el extranjero realizando estudios o viviendo de manera permanente en países como España, Francia, Alemania, entre otros.
}

Araucaria. Revista Iberoamericana de Filosofía, Política y Humanidades, año 19, n 37. Primer semestre de 2017. Pp. 381-403. ISSN 1575-6823 e-ISSN 2340-2199 doi: 10.12795/araucaria.2017.i37.18 
Desde la firma del alto al fuego en 1991bajo los auspicios de la ONU se está en la espera del Referéndum de Autodeterminación del pueblo saharaui ${ }^{6}$. Una lucha diplomática que ha llevado más de 25 años y que la ONU con su Consejo de Seguridad no ha dado soluciones concretas. El proceso de autodeterminación sigue bloqueado con un Marruecos que reafirma que la única salida al conflicto es aceptar su propuesta de autonomía al pueblo saharaui y el Frente Polisario de la RASD con el reclamo legítimo a un verdadero referéndum de autodeterminación que conlleve a su independencia.

A lo largo de los años que comprende la búsqueda del reconocimiento formal del derecho a la autodeterminación del pueblo saharaui, junto con la contienda bélica se ha dado un proceso institucional fallido que involucra a la comunidad internacional. Desde el punto de vista de la teoría cosmopolita de las Relaciones Internacionales, la promoción del diálogo y de los mecanismos institucionales supuestamente abonarían en favor de la soberanía de los pueblos que siguen peleando por ella. Teniendo en cuenta el principio cosmopolita de la gobernanza global mediante la búsqueda colectiva e institucional de un problema particular, la hipótesis de este artículo es que dichos ideales han fracasado debido a los intereses económicos y geopolíticos de las potencias involucradas. Estos intereses siguen estando por encima del derecho a la libre autodeterminación del pueblo saharaui y de los intereses colectivos que equivaldrían a la paz en la región. Por lo tanto, la lectura cosmopolita del conflicto es insuficiente por la rigidez de su contenido teórico. La propuesta del artículo es radicalizar la concepción tradicional de soberanía y plantear la ecosoberanía como un concepto que permita imaginar una propuesta nueva al derecho a la libre autodeterminación de los pueblos.

El artículo está dividido en cuatro apartados. En el primero se analizan los límites del cosmopolitismo respecto a la libre autodeterminación de los pueblos en general y se plantean los caminos teóricos propuestos por la ecosoberanía. En el segundo se hace una reseña histórica del conflicto saharaui en su búsqueda de consolidar una independencia otorgada por la comunidad internacional que no se ha cristalizado en los hechos. En el tercer apartado se analizan las acciones infructuosas de la comunidad internacional que ponen en evidencia la debilidad del cosmopolitismo como ideal aspiracional para resolver conflictos pendientes del siglo XX. Finalmente, en el cuarto apartado se reflexiona sobre la propuesta de la ecosoberanía como salida teórica al tema del Sahara Occidental.

\footnotetext{
${ }^{6}$ El censo para la realización del referéndum ha sido un elemento de discordia, sobre todo por Marruecos que ha obstaculizado y boicoteado todo este tiempo el proceso.
} 


\section{Ecosoberanía y el derecho a la autodeterminación de los pueblos}

Como se indicó en la introducción, el caso no resuelto de la libre autodeterminación del pueblo saharaui representa un reto factual al proyecto cosmopolita que plantea la posibilidad de libertad y soberanía como un derecho de alcances para toda la humanidad. El cosmopolitismo descansa en el ideal humano-céntrico que le otorga igualdad jurídica a todos los individuos, especialmente si la lucha por sus derechos y el reconocimiento de esa igualdad se da dentro de los marcos aceptados por la civilización occidental del diálogo, la negociación o la resolución pacífica de los conflictos. Sin embargo, el argumento de este artículo sostiene que, a pesar de transitar por el marco institucional, el Sahara Occidental no ha logrado conquistar su derecho a la soberanía, poniendo en entredicho la eficacia de la confianza cosmopolita en los valores que defiende. En este apartado se clarifica el marco conceptual que pone en debate la soberanía clásica defendida por el cosmopolitismo, y la posibilidad de expandir los alcances de la libre autodeterminación de los pueblos mediante el concepto de ecosoberanía.

El desarrollo de los Estados nacionales y la posterior construcción del sistema internacional, dice Martin Griffiths, tiene dos momentos históricos emblemáticos: la Paz de Westphailia (1648) que inauguró el sistema moderno basado en el principio de la soberanía territorial y la Revolución Francesa (1789) con el ideal universalista de la libre autodeterminación de los pueblos aplicable a toda la humanidad (Griffiths, 2003: 29-30). El consenso entre los estudiosos de las relaciones internacionales es que ambos momentos, y su posterior idealización discursiva universalista, son eminentemente eurocéntricos. Y ya fuera por la fuerza, la adopción, la repetición o la imitación, el modelo del Estado nacional soberano se globalizó, teniendo siempre a Europa como epicentro y faro de guía.

Por supuesto, el proceso de globalización del Estado nacional no estaría exento de interminables conflictos por reclamos soberanistas, secesionistas, particularismos étnicos, expansionismo territorial, guerras civiles y toda la gama de confrontaciones en el sistema internacional que tendrían como colofón la Segunda Guerra Mundial. Con la creación de las Naciones Unidas, la Asamblea General adoptaría el 14 de diciembre de 1960 la resolución 1514 conocida como la "Declaración sobre la concesión de la independencia a los países y pueblos coloniales"

Hasta aquí, las teorías liberales y cosmopolitas encuentran sustento para argumentar que, a pesar de sus deficiencias, el nuevo orden mundial de la posguerra perseguía el ideal de resolver los conflictos territoriales, nacionales y soberanistas por vías institucionales. Este argumento supone que, para la conformación de una sociedad internacional, primero habría que dotar a los 
Estados nacionales que la componen de la legitimidad necesaria que solamente podía recaer en el derecho de la libre autodeterminación de los pueblos. El camino para transitar hacia la soberanía también debía ser pacífico y para ello, las Naciones Unidas y la Corte Internacional de Justicia de La Haya tratarían de jugar el papel institucional que dicta la teoría cosmopolita.

Sin embargo, en el siglo XXI el problema de la libre autodeterminación de los pueblos sigue vigente, lo que permite recalcar la obsolescencia del ideal soberanista dominante en el corpus teórico internacionalista. Las aportaciones de Martin Griffiths y de Omar Dahbour abren nuevos horizontes de reflexión que podrían contribuir a la resolución del Sahara Occidental, el caso de estudio particular en este trabajo.

La pregunta que debe responderse es: ¿Cuáles son las deficiencias de las teorías internacionalistas dominantes que no logran resolver los contenciosos soberanistas del siglo XX en la actualidad? La respuesta es que la teoría descansa en la evidencia histórica de que en el sistema internacional hay dos principios en contienda por alcanzar el orden internacional: la soberanía territorial por un lado y el derecho a la libre autodeterminación de los pueblos por el otro (Griffiths, 2003: 34). El derecho a la soberanía territorial asume indirectamente que los Estados nacionales contemporáneos serían entidades históricas carentes de contradicción y que la sociedad internacional velaría por mantener su vigencia. El derecho a la libre autodeterminación de los pueblos propone el ideal de alcanzar la autonomía y la autogestión de pueblos, grupos étnicos y comunidades culturales que han quedado atrapadas dentro de las fronteras de los Estados nacionales. La contradicción de la que habla Griffiths recae en que ambos principios no son compatibles. Si la comunidad internacional pugna por la vigencia de los Estados nacionales contemporáneos, entonces el derecho a la libre autodeterminación de los pueblos sería negado a múltiples comunidades. En cambio, si el derecho a la libre autodeterminación de los pueblos es el ideal de la sociedad internacional, entonces sería imposible garantizar la integridad territorial de los Estados nacionales actuales. Retomando la pregunta formulada, en el caso de la teoría cosmopolita, su deficiencia recae en el hecho de que los procesos institucionales orientados a la libre autodeterminación de los pueblos se enfrentan a la cruda realidad de los intereses nacionales y del poder asimétrico de los Estados. Este dilema cabría en lo que David Held denomina la "paradoja de nuestros tiempos" (Held, 2010). Esta formulación no es otra cosa que reconocer y conceder la preminencia del comportamiento realista en las relaciones internacionales por encima de los incentivos cosmopolitas.

Un primer argumento desde el mundo de la teoría internacionalista es que para resolver dicho problema habría que romper "el vínculo histórico entre autodeterminación, nacionalismo y soberanía territorial" tanto a nivel político como teórico (Griffiths, 2003: 29). Griffiths apunta que, en el caso 
del realismo, el sistema internacional heredado de la Segunda Guerra Mundial y bipolar en su equilibro, encontró evidencia y razones suficientes -como una potencial confrontación nuclear- para argumentar que "el mejor método para lidiar con el problema de la libre autodeterminación de los pueblos era constreñirla a las fronteras territoriales de los estados nacionales existentes" (Griffiths, 2003: 39).

Por su parte, el pensamiento internacionalista liberal encontraría tras el final de la Guerra Fría razones para argumentar en favor de "ampliar los horizontes de la libertad humana y de los Estados nacionales" (Griffiths, 2004: 40-41). La postura sería la siguiente: en un escenario internacional enmarcado por los altos costos de la guerra y la ausencia de guerras entre potencias, se abrirían espacios para la resolución institucional de los conflictos nacionalistas y soberanistas vigentes. Las miradas más optimistas del cosmopolitismo y la gobernanza global igual apuntaban hacia el debilitamiento de las ortodoxias nacionalistas (Kenichi, 1995; Etzioni, 2001; Cooper, 2003) o su transformación hacia manifestaciones de nacionalismo cívico más incluyentes, tolerantes, democráticas y cosmopolitas (Zolo, 1997; Appiah, 2006; Held, 2010).

En un contexto de valores liberales se mantiene el problema de concentrar el derecho a la autodeterminación nacionalista a los Estados vigentes en menoscabo del derecho a la libre autodeterminación de las minorías. Para resolver este problema, Kymlicka (2004) propone el concepto de "países comunitarios" que reconozcan los derechos de sus minorías culturales. Como sugiere Kok-Chor Tan (2006: 85), el problema es que la mayoría de los estados no liberales niegan la igualdad de todas las comunidades y defienden la supremacía de la comunidad nacional por encima de las minorías. La autodeterminación sigue siendo vigente para los Estados nacionales existentes, pero no así, a pesar de la dialéctica liberal y cosmopolita, para las comunidades y culturas sub-nacionales (Tan, 2006: 85).

Al plantear de manera general las deficiencias teóricas tanto del realismo como del liberalismo y de sus expresiones cosmopolitas, se requiere dibujar, al menos un boceto analítico que intente superarlas para hacer asequible un ideal soberanista en el siglo XXI y que intente resolver los problemas de autodeterminación persistentes. En este sentido, las reflexiones de Omar Dahbour comienzan a dar pistas sobre esas posibles soluciones teóricas. Dahbour (2013) analiza el problema de la autodeterminación en la era de la globalización y no titubea en distinguir entre una comunidad política y una nación para aportar una definición postnacional al concepto de soberanía. Esta definición que Dahbour plantea en clara confrontación con el nacionalismo liberal y el cosmopolitismo se denomina Ecosoberanía (Ecosovereignty).

Ecosoberanía es un concepto que resalta la importancia de comunidades políticas diversas, incluyendo las comunidades indígenas, las regiones 
ecológicas y el desarrollo sostenible. Dahbour trata, con dicho concepto, de ir más allá del principio de la autodeterminación popular y de superar los límites teóricos de la polémica entre nacionalismo e internacionalismo que ha dominado la ética internacional desde hace ya varias décadas (Dahbour, 2013). Ecosoberanía plantea dos significados (Dahbour, 2013):

1) designa el derecho a la autogestión de diversos grupos humanos (peoples) que habitan dentro de los países establecidos con las fronteras y las normas clásicas del Estado nacional. Es aquí donde se justifica la prioridad que merecen a la independencia política y a la integridad de las regiones ecológicas y que se oponen a la lógica del Estado nacional, que históricamente ha subsumido a diversas regiones en detrimento de ellas. También implica una concepción robusta del derecho de los pueblos indígenas a las tierras y recursos necesarios para mantener sus estilos de vida distintivos;

2) establece el derecho de esos grupos humanos a ejercer soberanía sobre los recursos necesarios para hacer sostenibles sus vidas y hábitats. En este punto se plantea la necesidad de una soberanía racional sobre los recursos alimentarios que se denomina "el derecho de los pueblos a proteger su integridad ecológica y sus medioambientes locales."

Dahbour propone concebir a las regiones en su dimensión ecológica más que en su dimensión política. La trampa, dice Dahbour, de dividir a los grupos humanos o a los pueblos según concepciones legalistas de uniformidad política es que descuidan las bases materiales de las identidades políticas (Dahbour, 2013). La propuesta teórica de Dahbour señala que la autodeterminación de los pueblos terminó cediendo ante la hegemonía de la autodeterminación nacionalista, y esto es fruto de la contingencia histórica, por tanto, no es inevitable. Y al hablar de la coyuntura histórica, Dahbour propone que las condiciones del colonialismo europeo, así como los procesos de descolonización han cambiado, destaca la necesidad de una nueva epistemología del derecho a la libre autodeterminación de los pueblos.

Dahbour no escapa del ideal liberal de universalizar la libre autodeterminación de los pueblos hasta los grupos humanos más pequeños y distantes de las formas de vida de la forzada modernización global. Podría considerársele un defensor de la autodeterminación de las comunidades ecológicas y culturales que precisamente la modernización homogeneizadora de corte eurocéntrico ha despreciado. Se podría argumentar que se trata de un giro conservador que pretende mantener la viabilidad de los grupos humanos que no necesariamente desean o pueden asimilarse a los procesos urbanizadores de la experiencia humana. Pero también se puede señalar que la propuesta de Dahbour desea llevar al límite el ideal humano céntrico de las libertades plenas pasando a una nueva etapa que supere las restricciones del modelo estado céntrico. 
Esta apuesta teórica coincide con el ideal soberanista del Sahara Occidental. En la búsqueda de soluciones institucionales del siglo XX, el Sahara Occidental sigue esperando una resolución cosmopolita que no parece viable, ya que el cosmopolitismo y su versión política denominada gobernanza global, sucumbe fácilmente a las pretensiones totalizadores del modelo del Estado nacional y a las asimetrías de poder en un sistema internacional que no es ni democrático ni incluyente.

\section{La descolonización infructuosa y el ideal cosmopolita en entredicho}

La cuestión del Sahara Occidental plantea dos escenarios: primero, que todo su proceso de descolonización se ha realizado bajo los marcos institucionales de los organismos multilaterales fruto del pacto internacional de la posguerra; segundo, el proceso se ha estancado precisamente por la ineficacia de dichos organismos multilaterales, por las asimetrías de poder entre Marruecos y la población saharaui, por la constante negativa francesa de aprobar resoluciones del Consejo de Seguridad de las Naciones Unidas. En suma, el problema no se ha resuelto por la falta de voluntad de los actores políticos involucrados. Se trata de la crónica de tema pendiente de resolución en el sistema internacional que denota una distorsión entre los planteamientos cosmopolitas y la realidad.

El Sahara Occidental fue territorio colonial español entre 1884-1976 establecido en el reparto colonial africano en la Conferencia de Berlín (18841885). El territorio colonial del Sahara español estaba conformado por la región de Tarfaya al norte ${ }^{7}$ como protectorado mientras que el resto del territorio era considerado bajo el estatus de colonia estableciéndose una clara división administrativa en un mismo territorio geográfico, cultural y étnico. El territorio pasó a estatus de provincia tardíamente -1957-, cuando ya la mayoría de los territorios africanos colonizados estaban en proceso de acceder a la independencia.

Esto significó una funesta descolonización en manos de una agónica dictadura franquista y un fuerte movimiento nacionalista que llevó a la creación en 1973 del Frente Popular de Liberación de Saquía el Amra y Río de Oro -Frente Polisario-. Las tensiones se recrudecieron cuando ya a finales de 1974 España proclama que daría la autodeterminación al Sahara mediante referéndum. Ante esto -Marruecos con Hassan II a la cabeza- propone la participación jurídica de la Corte Internacional de Justicia (CIJ) dilatando la posibilidad de independencia de los saharauis. ${ }^{8}$ Finalmente, el dictamen de

\footnotetext{
${ }^{7}$ Para más información Ver: Ignacio Cobo Fuentes (2011).

${ }^{8}$ Esta maniobra significó el pedido de la Asamblea General de la ONU a España de aplazar el referéndum y esperar a los resultados de la CIJ. Por su parte, Marruecos inició un lobby político en Estados Unidos para garantizar apoyo a su proyecto político expansionista en caso de lucha armada, 
la CIJ se dio el 16 de octubre de 1975 estableciendo que no había "ningún lazo de soberanía territorial entre el territorio del Sahara occidental y el reino de Marruecos o la entidad de Mauritania", por lo que significaba que debía aplicarse la resolución 1514 de 1960 para la descolonización del Sahara Occidental mediante la expresión libre de la voluntad de los habitantes del territorio. Lo que podría haber sido un éxito para el Sahara Occidental, en realidad fue pírrico ya que la CIJ emitió un dictamen consultivo, es decir, no vinculante. Por esta razón, ninguna de las partes involucradas estaría obligada a cumplir ninguna indicación de la corte.

Si bien no fue vinculante, el dictamen de la CIJ legitimó los reclamos soberanistas saharauis. Y, precisamente por no ser vinculante, Marruecos insiste en su soberanía sobre el territorio y expresa que el Sahara Occidental nunca había existido como entidad jurídica y que siempre había sido parte integral de Marruecos o Mauritania. ${ }^{9}$ El rey Hassan II se presentó el 16 de octubre de 1975 a los medios de comunicación dándose como el triunfador y llamando a los pobladores marroquíes a realizar una marcha para ocupar el territorio del Sahara conocida como la "Marcha Verde" hacia el Sahara Occidental que reunió alrededor de 350 mil marroquíes en un acto simbólico de reconquista del territorio ${ }^{10}$. Ante esta situación la tensión se agudiza. El Consejo de Seguridad por su parte, le pide a Hassan II que detenga la marcha y España en términos prácticos finalmente capitula ante Marruecos firmando una Declaración de Principios entre España, Marruecos y Mauritania conocido como el "Acuerdo Tripartita de Madrid" donde el rey Juan Carlos I transfiere la administración temporal tripartita del Sahara Occidental por España, Marruecos y Mauritania ${ }^{11}$. Sin dudas, este acuerdo político ayudó a la consecución del proyecto expansionista marroquí secundado por Mauritania y le conservaba a España sus derechos de pescar libremente en el rico litoral saharaui, y mantener sin problema sus enclaves de Ceuta y Melilla. De esta manera, España abandonaba definitivamente el territorio en 1976 sin hacer cumplir el Mandato de la Organización de Naciones Unidas, del derecho a los pueblos a la libre autodeterminación. El fracaso del arreglo institucional multilateral conllevó a la guerra de Marruecos y Mauritania con el Frente Polisario hasta la retirada de Mauritania en 1979 y la firma del Plan de Paz con Marruecos en 1991.

mostrando al Frente Polisario como una amenaza a los intereses estadounidense en la región.

${ }^{9}$ Ver: Fernández (1979, p.110-112).

${ }^{10}$ Esta marcha significó el peregrinaje de hombres y mujeres en condiciones precarias hacia las tierras saharauis en nombre del profeta y el Corán en medio del frío y el hambre. Muchos murieron por cólera, disentería y enfermedades gastrointestinales y en ese tiempo muchos la catalogaron como la "marcha del hambre".

${ }^{11}$ Hay que recordar que la validez jurídica de este Acuerdo ha sido cuestionada por la propia Organización de Naciones Unidas. El territorio del Sahara Occidental sigue figurando en la lista de la ONU como único territorio español pendiente de descolonización. 
Desde finales de la década de los ochenta se comenzó un proceso de negociación ${ }^{12}$ entre las partes ante el desgaste de la guerra- impulsado nuevamente por la resolución 43/33 de la Asamblea General de la ONU aprobada en noviembre de 1988 en la que se reafirmaba el derecho del pueblo saharaui a la autodeterminación y a la independencia, y se pedía a las partes en conflicto negociaciones directas para llegar a un alto el fuego y crear las condiciones para la preparación del referéndum bajo el patrocinio de la ONU con la creación e instalación de la Misión de Naciones Unidas para el Sahara Occidental (MINURSO).

Esta solución se da en el contexto de fin de la Guerra Fría y ante la emergencia de un nuevo orden internacional en que la tesis de la lucha armada quedaría relegada en la resolución pacífica de conflictos, imponiéndose la lógica de las Misiones de Operaciones de Paz diseñados por la ONU y confirmadas por el Consejo de Seguridad. Finalmente, en 1990, el Frente Polisario y el Gobierno de Marruecos con mediación de la ONU y la entonces Organización para la Unidad Africana (OUA) acordaron un Plan de Paz que establecía un alto al fuego -hecho efectivo desde septiembre de 1991-, la creación e instalación de la MINURSO y la preparación de un referéndum de autodeterminación ${ }^{13}$.

Si bien desde 1992, no se suceden operaciones bélicas importantes, las fuerzas militares de ambos bandos limitado a través del Muro continúan sus labores de vigilancia en sus zonas. En el campo político, el proceso de paz ha tenido altibajos importantes con un dilatado y nunca realizado referéndum por falta de acuerdo entre las partes, especialmente en cuanto al número de electores que debían participar en este proceso ${ }^{14}$. En 1997, el Consejo de Seguridad asignó a James Baker como Representante Especial del entonces Secretario General Kofi Annan. Su propuesta inicial conocida como Plan Baker, se encomiaba por la autonomía del Sahara dentro de Marruecos aun cuando incluía la convocatoria en cinco años de un referéndum final. Proposición que no fue compartida por el Frente Polisario ${ }^{15}$ pues concordaba con la tesis marroquí del rey Hassan II.

La imposibilidad de llegar a acuerdo alguno entre las partes que supusiera la aprobación de alguna de estas vías, llevó al Representante Especial, James Baker $^{16}$, a proponer en enero de 2003, un nuevo Acuerdo Marco de autonomía

\footnotetext{
${ }^{12}$ Tomar en consideración la incidencia de la realidad argelina que significó la en la reducción del apoyo material al Frente Polisario.

${ }^{13}$ Para esto se creaba una Comisión de Identificación por la MINURSO para la actualización del censo español de 1974 con el propósito de concretar la base de votantes que tenían derecho a la participación.

${ }^{14}$ Con Mohamed VI, Marruecos intervino en la alteración de cifras del censo electoral. Los criterios de identificación establecidos en el plan de paz de la MINURSO. Ver: Cobo (2006).

${ }^{15}$ Desde la llegada al poder de Buteflika en 1999 el apoyo argelino se reforzó apostando por la garantía del referéndum. No hay dudas, que el apoyo de Argelia también define intereses nacionales y regionales, tomando en cuenta que es uno de los países más importantes de la región.

${ }^{16}$ Para profundizar en el tema se puede revisar Lurdes Vidal (2003).
} 
modificada ${ }^{17}$. Aquí se partiría de un proceso de elecciones autonómicas en el que se elegirían lo que las Naciones Unidas denominaban "Autoridad del Sahara Occidental", repartiéndose con el Reino de Marruecos las competencias sobre la antigua colonia. Los votantes serían solamente los verdaderos saharauis identificadas como tales por la Comisión de Identificación de la MINURSO y los saharauis refugiados en países vecinos ${ }^{18}$. Por su parte, Marruecos conservaría durante este periodo, la soberanía sobre el territorio y seguiría teniendo competencia en las áreas de defensa nacional y de relaciones exteriores. En cuanto a la celebración del dilatado referéndum se establecía, su celebración no antes de cuatro años y no después de cinco. Con este ofrecimiento pragmático, se buscaba compensar los anhelos de ambas partes en conflicto.

Sin embargo, este plan tampoco dio los resultados esperados ${ }^{19}$ y con la dimisión de Baker se ponía fin a siete años de búsquedas de soluciones al conflicto. Por su parte, Marruecos desistió de su plan dilatorio y planteó que su única concesión consistía en negociar un estatuto de autonomía para el "Sahara marroquí" cuyos límites estarían, de acuerdo con "la soberanía y la integridad territorial del Reino". Los presupuestos marroquíes fueron muy tomados en cuenta con la llegada de Peter Van Walsum al cargo cuando trató con recetas dogmáticas, prácticas y realistas -según él-, convencer a los saharauis que su única solución para superar el impasse del conflicto era la renuncia a sus derechos legítimos y apostó como base de la negociación la oferta de autonomía de Marruecos a los saharauis ${ }^{20}$, lo cual resultó menos fructuoso. Posteriormente, llegó el nombramiento de Christopher Ross en el 2009 (El País, 2009) manteniéndose en el cargo después de ocho años -renunciando en marzo 2017- y sin lograr desbloquear el conflicto ${ }^{21}$.

Hay que agregar que además de las infructuosas negociaciones de los Altos Encargados de la Misión en el Sahara, la MINURSO tampoco ha logrado concretar la consulta de autodeterminación y de imponer un mandato de monitoreo de los derechos humanos en la zona ocupada, gracias al persistente veto de Francia en el tema. Además, con la visita de Ban Ki-moon

\footnotetext{
${ }^{17}$ NNUU, "Peace Plan for Self-Determination of the People of Western Sahara". Enero de 2003.

18 También se tomarían en cuenta los colonos marroquíes que hubieran residido permanentemente en el Sahara occidental desde el 30 de diciembre de 1999.

${ }^{19}$ Los más reticentes a este nuevo plan fueron los marroquíes y al no contar con la anuencia de las partes, el 11 de junio de 2004, James Baker presentaba su dimisión.

${ }^{20} \mathrm{Su}$ mandato no fue renovado por pedido del Frente Polisario.

${ }^{21}$ Estos funcionarios son los mediadores encargados de encauzar rondas de negociaciones entre las partes. Hay que añadir en este sentido, que en marzo del 2016 -por primera vez en su mandato de 10 años- el entonces Secretario General de la ONU -Ban Ki-moon- visita los campamentos saharauis para abrir una puerta a impulsar la negociación, la continuidad y la efectividad de la Misión de las Naciones Unidas para el referéndum del Sahara Occidental (MINURSO) que no tiene competencia en materias de vigilancia en la defensa de los derechos humanos y menos aún medidas de sanción contra las maniobras dilatorias de Marruecos para concretar el referéndum. Visita que no significó cambios sustanciales y si provocó tensiones y malestares con Marruecos por la referencia del Secretario de un Sahara ocupado.
} 
a los campamentos saharauis, las tensiones con Marruecos se intensificaron provocando la exigencia marroquí de la salida de ochenta y cuatro miembros del personal de la MINURSO y anunciando la cancelación voluntaria que destina a su funcionamiento ${ }^{22}$ (Monhsen-Finan, 2016).

A fines del 2016, continuó una escalada de tensión en la región, entre las tropas marroquíes y el Ejército de Liberación Saharaui en la región del El Gueguerat ${ }^{23}$ finalizando con la recuperación del territorio por las tropas saharauis y la reapertura de la frontera con Mauritania (El Confidencial Saharaui, 2016). Ante las tensiones crecientes debido al impasse del conflicto, las presiones marroquíes y la dimisión del Enviado Especial para el Sahara Christopher Ross- el nuevo presidente de la RASD, Brahim Gali ${ }^{24}$, llegó a la sede de Naciones Unidas para reunirse con el nuevo Secretario General de la ONU, António Guterres para abordar la cuestión y pedir avances rápidos en el proceso político (EFE, 2017).

No obstante, todos los caminos institucionales que se enarbolan en el ideal cosmopolita de gobernanza, las posiciones de las partes son antagónicas y no vislumbran una solución por vías institucionales. Marruecos, desde 2007, plantea que la negociación parte de la autonomía del Sahara de acuerdo a la soberanía y la integridad territorial del Reino marroquí. Es decir, incorporar al Sahara Occidental a la soberanía de Marruecos. Sin dudas, ante la superior capacidad de Marruecos de defender y buscar aliados de su posición, su labor diplomática a la cabeza del rey Mohamed $\mathrm{VI}^{25}$, ha estado encaminada a presentarse como el aliado estratégico, defensor de los intereses de occidente en el norte de África y pieza fundamental en la resolución del conflicto en Medio Oriente. La posición saharaui, por su parte, es defender su derecho a la libre autodeterminación mediante el referéndum, sin descartar la opción de retomar el conflicto armado si las dilatadas negociaciones, acciones y posiciones de los mediadores internacionales siguen perdurando.

${ }^{22}$ También amenazó con retirar sus contingentes en sus operaciones de mantenimiento de paz en el continente. Marruecos aporta cerca de 2.300 cascos azules a la Misión de Estabilización de las Naciones Unidas en la República Democrática del Congo (MONUSCO).

${ }^{23} \mathrm{El}$ incidente se produjo porque en este territorio los marroquíes estaban asfaltando un tramo de $3,8 \mathrm{~km}$ fuera de los muros del Sahara Occidental ocupado y cerca de los territorios colindantes con Mauritania. Esta tensión llevó una reunión de urgencia del Consejo de Seguridad y conllevó el envío de militares de la MINURSO a la zona. Esta provocación llevó casi a un enfrentamiento entre los militares de ambas partes. El Ejército saharaui sigue resguardando la zona.

${ }^{24}$ La visita se clausuró el 17 de marzo de este año y se trató de la primera visita del presidente de la RASD desde que fue nombrado el julio de 2016. Igual hay que considerar que cada año en este tiempo, el Consejo de Seguridad aborda la situación del Sahara y la renovación de la misión de la ONU-MINURSO- en la zona.

${ }^{25}$ Mohamed VI ha seguido la postura que desempeño su padre Hassan II ante este conflicto durante cuarenta años. Recurre al lobby político mediante todo tipo de prácticas para atraer el apoyo de países desde financiamiento a asociaciones, haciendo donaciones a los países y dando viajes de lujo a académicos o políticos. 
Los hechos narrados hasta aquí corroboran el planteamiento de que el proceso descolonizador en el Sahara Occidental ha sido infructuoso y pone en entredicho el ideal cosmopolita de la libre autodeterminación de los pueblos. Esto se explica por tres razones fundamentales. La primera consiste en señalar que los organismos multilaterales heredados tras el final de la Segunda Guerra Mundial fueron fundados sobre la base clásica de los Estados nacionales, otorgándoles a ellos la facultad exclusiva de la soberanía. Por esta razón, plantear procesos de libre autodeterminación rompe con la lógica de mantener vigente el actual orden internacional, especialmente cuando se ven involucradas potencias regionales como es el caso de Marruecos. La segunda razón es que los organismos multilaterales carecen de herramientas que les faculten para llevar hasta sus últimas consecuencias incluso los reclamos soberanistas legítimos como en el caso del Sahara Occidental. Y la tercera es una paradoja: el ideal cosmopolita plantea que la libre autodeterminación de los pueblos deberá construirse sobre bases institucionales sólidas, sobre procesos democráticos como el referéndum o el plebiscito y evitando cualquier amenaza de conflicto entre los involucrados o hacia los vecinos. Tal ha sido el comportamiento del pueblo del Sahara Occidental. Sin embargo, la evidencia internacional reciente corrobora que es en los escenarios de escalada del conflicto como en la ex Yugoslavia o en Timor Oriental, cuando los organismos multilaterales se involucran con soluciones definitivas a los reclamos soberanistas. En este sentido, resulta paradójico que habiendo seguido los planteamientos cosmopolitas que auguran un régimen de gobernanza global institucional, la solución para un Sahara Occidental libre siga condenada a la inacción.

La otra paradoja descrita por David Held, "la paradoja de nuestros tiempos", plantea que a pesar de que los problemas colectivos requieren soluciones colectivas, los Estados nacionales siguen intentando preservar sus intereses en situaciones de emergencia, riesgo, fallas en el sistema o conflictos. Por lo tanto, sigue privando un comportamiento realista que contradice el ideal cosmopolita. A continuación, se detallan los intereses particulares que dificultan la resolución colectiva del conflicto en el Sahara Occidental.

\section{La comunidad internacional y "la paradoja de nuestro tiempo"}

La espera de la realización del referéndum y las dilatadas y pocas consensuadas negociaciones han prolongado y han perpetuado la ocupación marroquí del Sahara Occidental. La responsabilidad de este impasse se debe, fundamentalmente, a la falta de voluntad de los actores internacionales preponderantes. En este apartado se evidencian los límites realistas al 
ideal cosmopolita, expresados en las posiciones actuales de las potencias involucradas, no tanto en el conflicto, sino en la construcción de su solución.

En la actualidad la posición soberanista del Sahara Occidental sostiene que la única salida es la celebración del referéndum de autodeterminación según la legalidad y los Acuerdos de Paz aprobados por la ONU en 1991. Sigue siendo una postura cosmopolita en pro de la solución institucional al conflicto.

Por su parte, Marruecos defiende el proyecto de un estatuto de autonomía, presentado en 2007 ante el Consejo de Seguridad de la ONU, como base para cualquier negociación. La propuesta va en tono con el ideal soberanista clásico de otorgarle autonomía al Sahara Occidental bajos los límites y el poder del reino de Marruecos. El territorio debe tener un nivel de autonomía, pero no de Independencia.

Ambas posiciones son irreconciliables y no se vislumbra una solución desde el punto de vista tradicionalista y Estado céntrico de Derecho Internacional. La decisión sobre el derecho a la autodeterminación, en virtud del dictamen consultivo de la CIJ, corresponde exclusivamente a los habitantes del Territorio no autónomo. Las posiciones y las interpretaciones de la comunidad internacional se describen a continuación.

Empecemos por señalar que hay un consenso académico en otorgarle la raíz del conflicto a España (Diego,1988, 1991; Barona (2005); Algueró (2006); Barreñada y Ojeda (Coord), 2016) que de manera irresponsable no terminó sus compromisos como potencia colonizadora en el territorio cediendo el mismo a las ambiciones expansionista marroquíes. Desde ese momento hasta hoy, la postura de los sucesivos gobiernos democráticos españoles ha sido vacilante. Practica su política de neutralidad activa, simpatiza con el Frente Polisario y sus reivindicaciones, pero se inclina por mantener relaciones estables con Marruecos. España estima que la prioridad es avanzar en el proceso político, y que los esfuerzos de la comunidad internacional deben concentrarse en ayudar a las partes, Marruecos y el Frente Polisario, a acordar una solución política justa, duradera y mutuamente aceptable, que prevea la libre determinación del pueblo del Sahara Occidental en el marco de disposiciones conformes a los principios y propósitos de la Carta de las Naciones Unidas. Sin embargo, tiene una postura neutral respecto al conflicto del cual es responsable. Bajo telón, la diplomacia española apoya a Marruecos con su propuesta de autonomía y en muchas ocasiones alineándose a Francia. Se esfuerza por evitar que la Unión Africana desempeñe un papel crucial en la negociación y que el proceso negociador siga en manos de la ONU para evitar interferencias.

En el caso francés, Francia es el aliado incondicional de Marruecos. Siempre ha tenido una postura pro-marroquí ante el conflicto y ésta se ha visto reflejado en cada veto de Francia en el Consejo de Seguridad de la ONU. Es partidario de una solución al conflicto a partir de las bases establecidas por 
los marroquíes. Francia considera que el plan de autonomía presentado por Marruecos al Secretario General de la ONU en abril de 2007 es una base seria y creíble para una solución negociada y, al mismo tiempo, apoya el papel de la MINURSO.

La Unión Europea apoya a la ONU para el logro de una solución política y justa en un acuerdo mutuo que provea la libre autodeterminación del Sahara Occidental. De manera oficial promueve la resolución del conflicto, el respeto al pueblo saharaui a su libre autodeterminación y mantiene programas de ayuda humanitaria y de cooperación al desarrollo. Al mismo tiempo mantiene relaciones comerciales con Marruecos. Si bien su postura es clara, su actuación ambigua al no confrontar a Francia ni a Marruecos, éste último, aliado europeo en varios frentes, desde el comercial y migratorio hasta en materia de seguridad regional.

La Unión Africana (UA) es otro actor institucional relevante en el estado actual del conflicto. Considera que España sigue siendo la potencia administradora en el Sahara, aunque no pueda ejercer esa labor por el control de Marruecos. Reclama a la MINURSO que asuma la tarea de supervisar la situación de los Derechos Humanos, como sucede con el resto de las misiones de la ONU de mantenimiento de paz. Y reclama que la Misión organice el referéndum sobre el Sahara, tal y como establece su propio nombre. Apoya abiertamente al Frente Polisario y la RASD, la reconoce, es miembro pleno del organismo. Por su parte, el Consejo de Paz y Seguridad (PSC) de la UA tiene un enviado especial para el Sahara Occidental y está de acuerdo que el Consejo de Seguridad asuma las responsabilidades y tome las medidas para resolver rápidamente el conflicto y encuentre soluciones al respeto a los derechos humanos y a la explotación ilegal de los recursos naturales del territorio ${ }^{26}$.

Acompañando a la UA, y manteniendo un papel también importante, Argelia desempeña un papel destacado en el conflicto. Es aliado saharaui y ha sido el apoyo histórico del Frente Polisario, de la RASD y de la población saharaui desplazada hacia sus fronteras tras la ocupación marroquí.

${ }^{26}$ La UA es una organización política de los Estados Africanos cuyo objetivo es lograr la integración política y económica de sus países miembros. Surge en el 2001 como continuación de la Organización para la Unidad Africana (OUA) creada en 1963. Hasta esta última cumbre -la XVIII celebrada del 30 al 31 de enero de 2017-, se acordó la readmisión de Marruecos a la organización. Desde 1984 -con el entonces monarca Hassan II- se había retirado dado el reconocimiento por parte del bloque africano de la República Árabe Saharaui Democrática (RASD). La UA, es el único organismo internacional que reconoce como Estado a la RASD. Como resultado de esta última Cumbre, la organización aceptó en su seno a Marruecos. La decisión de Marruecos de solicitar la reintegración a la UA sin condiciones previas ha sido un empeño personal de Mohamed VI. Para él, la ausencia de Marruecos en la organización representaba un autoexilio y tenía que ser rectificado. Esta postura vino acompañada de una aguda campaña diplomática y un plan de expansión de sus actividades económicas y comerciales en la región, sobre todo en los países de África occidental francófona. La readmisión de Marruecos en la UA significa la llegada del conflicto saharaui al seno de la organización y la posibilidad de que la UA presione firmemente a Marruecos para llegar a un acuerdo del conflicto. Aunque no parece tan claro ese horizonte más la UA le puede servir de plataforma para afianzar no solo su posición en el continente con un mensaje conciliador sino también aumentar su influencia internacional. 
Estados Unidos, por su parte, ha sido sin dudas uno de los principales aliados de Marruecos en la región también en materia geopolítica y de seguridad. Históricamente ha recibido un apoyo económico y militar que ha ayudado su postura expansionista sobre el Sahara. En el contexto de guerra fría, el Sahara aliada con Argelia, representaba la irradiación de los ideales socialistas en la región por lo que EEUU mantuvo lazos estrechos con la monarquía marroquí manteniendo alejada la amenaza independentista ${ }^{27}$. Con el derrumbe del campo socialista y el fin de la guerra fría, la amenaza en la región cambió de significado. Ahora era la lucha contra el terrorismo lo que caracterizada las dinámicas con la zona donde Marruecos juega un papel importante, aprovechándose de esas estrategias globales geopolíticas para perpetuar su ocupación en el Sahara. ${ }^{28}$

Finalmente, las Naciones Unidas reconocen al Frente Polisario como representante legítimo del pueblo saharaui y apoya su lucha de liberación nacional y salida pacífica del conflicto, pero se plantea complaciente con hacer cumplir a Marruecos sus compromisos y propuestas. El Consejo de Seguridad, ha cedido a las manipulaciones marroquíes para no hacer valer la consulta popular de autodeterminación y dar cabida a sus intentos anexionistas de negociar un estatuto de autonomía del Sahara en el marco de la soberanía del Reino de Marruecos y su unidad nacional. La ONU -al que le concierne la responsabilidad de mantenimiento de la paz y resolución- queda atrapado en el Consejo de Seguridad, donde Marruecos cuenta con fuertes influencias políticas y económicas. La inacción en temas prioritarios para la protección y seguridad de la población saharaui como las competencias en materia de derechos humanos de MINURSO, entre otras, evidencia la complicidad de las grandes potencias -especialmente el apoyo incondicional de Francia $^{29}$ - en sus posiciones ante la situación saharaui. De tal manera, que las múltiples resoluciones de Naciones Unidas que han confirmado el derecho a la autodeterminación del pueblo saharaui no han servido de nada pues han quedado sistemáticamente incumplidas. La comunidad internacional lo sigue aceptando y la democracia liberal sigue negando el derecho de la autodeterminación.

\footnotetext{
${ }^{27}$ Para más información de la posición de Estados Unidos con respecto al conflicto Ver: Zoubir, Yahia (2009).

${ }^{28}$ Jugando con esta dinámica ha hecho propaganda política en contra de los saharauis percibiéndolos como una amenaza y poniendo a los campamentos saharauis como un espacio que fomenta el tráfico ilegal y reclutamiento de organizaciones terroristas.

${ }^{29}$ Francia se ha caracterizado por tener una postura pro marroquí. No es su interés contar con un nuevo estado, menos no francófono y vecino de Marruecos. Además, no hay que olvidar que, para Francia, el Sahara occidental siempre representó una piedra incómoda en su espacio colonial occidental africano.
} 


\section{Soberanía clásica versus ecosoberanía y el Sahara Occidental}

En este apartado se pretenden responder dos preguntas que se desprenden de los hechos descritos y del marco teórico propuesto para entenderlos: 1 ¿Cuáles son las razones de que el derecho a la autodeterminación de los pueblos en su versión clásica no obtenga resultados favorables para la solución de los reclamos soberanistas del Sahara Occidental en un proceso de descolonización infructuoso; 2) ¿Qué plantea el concepto de ecosoberanía propuesto por Omar Dahbour para plantear un ideal soberanista asequible y en concordancia con un proyecto cosmopolita para rediseñar los equilibrios de poder en el siglo XXI?

Para responder a la primera pregunta es necesario recalcar que tanto la libre autodeterminación de los pueblos como soberanía en su forma clásica siguen recayendo en el Estado nacional como el actor privilegiado de las relaciones internacionales. España, Francia, la Unión Europea y Estados Unidos prefieren mantener como aliado estratégico a Marruecos antes de proceder a cristalizar la soberanía saharaui. En términos poblacionales, los saharauis representan un problema menor ante el riesgo de desestabilizar la región y entrar en antagonismo político con Marruecos.

También hay intereses económicos que explican "la paradoja de nuestros tiempos" en el caso del Sahara Occidental. Dicho territorio representa para Marruecos, y en consecuencia para los demás actores, largas costas hacia el Atlántico con ricos bancos pesqueros, la existencia de la mayor reserva mundial de fosfatos y yacimientos de petróleo, gas y uranio (Hernández (2014); Garduño (2014).

Para argumentar una posición teórica en favor de la libre autodeterminación del pueblo saharaui, como se ha indicado antes, el concepto de soberanía clásico ya no es operacional. Esto se sostiene por las siguientes razones. Si bien el ideal cosmopolita de una resolución institucional del conflicto no se ha alcanzado, el planteamiento cosmopolita de pensar el nuevo orden internacional más allá del Estado nacional resulta funcional. Así como las relaciones internacionales reconocen nuevos actores, también podrían reconocer los reclamos soberanistas de diversos pueblos, grupos humanos, y culturales sin necesidad de menoscabar la autoridad de los Estados nacionales. Por supuesto, los Estados nacionales, celosos de su poder, plantearían una respuesta conservadora ante la posibilidad de disminuir su poder efectivo en favor de la autogestión de dichos grupos humanos. Argumentan el riesgo de que las nuevas entidades resulten fallidas y caigan en manos del crimen organizado o del terrorismo; plantean la imposibilidad de la autogestión de grupos humanos poco numerosos en territorios inhóspitos; y sugieren el peligro del barril sin fondo de los reclamos soberanistas que sugiere que ante la independencia de una comunidad, nada garantizaría que dicha comunidad se pudiera mantener vigente si nuevos reclamos soberanistas aparecieran amenazando su nueva y frágil integridad. 
Independientemente de estos planteamientos, los reclamos soberanistas siguen vigentes y no parecen claudicar en las primeras décadas del siglo XXI. Para contestar la segunda pregunta, Ecosoberanía es un concepto que resalta la importancia de comunidades políticas diversas, incluyendo las comunidades indígenas, las regiones ecológicas y el desarrollo sostenible. Dahbour trata, con dicho concepto, de ir más allá del principio de la autodeterminación popular y de superar los límites teóricos de la polémica entre nacionalismo e internacionalismo que ha dominado la ética internacional desde hace ya varias décadas (Dahbour, 2013).

Al resaltar la importancia de comunidades políticas diversas, el pueblo saharaui podría reivindicar su calidad de grupo humano en particular, pero sin ser antagonista de la pretendida unidad política de Marruecos. Este país, por el contrario, sostiene que sólo la autonomía bajo su control resultaría legítima y viable para el pueblo saharaui. La posición de Marruecos niega el derecho a la autogestión del pueblo saharaui y la supedita al Estado nacional, al que considera depositario único de cualquier forma de soberanía.

Es aquí donde se justifica la prioridad que merecen a la independencia política y a la integridad de las regiones ecológicas que, como sostiene Dahbour, se oponen a la lógica del Estado nacional, que históricamente a subsumido al poder central a diversas regiones y sub grupos culturales en su detrimento. También implica una concepción robusta del derecho de los pueblos indígenas a las tierras y recursos necesarios para mantener sus estilos de vida distintivos toda vez que los Estados nacionales no han demostrado ni su eficacia ni su compromiso con la preservación de la naturaleza y la construcción de modelos sostenibles de explotación racional de los recursos.

Contrario a lo que propone Marruecos, es decir, una administración de la riqueza natural de la región del Sahara Occidental en función de la gran comunidad nacional marroquí, Dahbour propone reconocer el derecho de esos grupos humanos a ejercer soberanía sobre los recursos necesarios para hacer sostenibles sus vidas y hábitats. Como ya se indicó, se trataría de una soberanía racional sobre los recursos alimentarios que se denomina "el derecho de los pueblos a proteger su integridad ecológica y sus medioambientes locales." En este sentido, la propuesta teórica de Dahbour nos permite concebir al Sahara Occidental en su dimensión ecológica más que en su dimensión política.

El contraargumento realista y conservador es que todas las sociedades deberían integrarse dentro de un modelo racional homogeneizador en el que prevalecieran los derechos civiles y no los derechos religiosos o étnicos. La potencial debilidad del concepto de ecosoberanía es que, con facilidad, se le podría calificar de una propuesta "etnonacionalista". Sin embargo, la debilidad del concepto de soberanía nacional es que precisamente se ha encargado de debilitar y desprestigiar los matices que diferencian a los subgrupos étnicos 
o religiosos. Y esto fue posible porque las bases de la descolonización, en América, Asia y África, se dieron sobre las condiciones del colonialismo europeo, que terminó privilegiando a unos grupos sobre otros.

Quizá el argumento más fuerte de la ecosoberanía recaiga en el hecho de que los reclamos soberanistas en el mundo en el siglo XXI no apuntan a disminuir, ni siquiera en los "espacios privilegiados" de la racionalidad modernizadora de occidente. Tan solo en Europa Escocia, Cataluña, Padania, Véneto o Kosovo nos recuerdan que el derecho a la libre autodeterminación de los pueblos es una cuestión en disputa incluso en el corazón del modelo del Estado nacional moderno. Ante la inevitabilidad de los reclamos soberanistas, la imaginación teórica tendrá que ajustar sus consideraciones, especialmente si el ideal cosmopolita, como en el caso del Sahara Occidental, ha resultado infructuosos y amenaza, con su estancamiento, en recrudecer el conflicto incluso hasta con la confrontación bélica.

Como se planteó en la hipótesis de este artículo, el principio cosmopolita de la gobernanza global, que aspira a una solución colectiva a un problema particular como es el caso de la libre autodeterminación del pueblo saharaui, ha sido un proceso institucional e infructuoso. Los intereses nacionales de las potencias involucradas siguen estando por encima del derecho a la libre autodeterminación del pueblo saharaui, lo que impide el establecimiento de un Estado nacional y el reconocimiento de su soberanía a pesar de haberse legitimado por la vía de la CIJ y de la ONU. Al mismo tiempo, los intereses colectivos que equivaldrían a la paz en la región, también están supeditados a los intereses de las potencias implicadas. Una lectura ecosoberanista del conflicto del Sahara Occidental deber ser, junto con otras más, una apremiante necesidad teórica ante los cambios del sistema mundial y la pérdida de vigencia de las miradas ortodoxas, que no logran superar la lógica estado céntrica a pesar de la evidencia que constata su obsolescencia. 


\section{Referencias bibliográficas:}

Algueró Cuervo, José Ignacio (2006), EL Sahara y España: claves de una descolonización pendiente, Idea Ediciones, España.

Appiah, Kwame Anthony (2006) Cosmopolitanism: Ethics in a World of Strangers, London, Penguin/Random House.

Barreñada Bajo, Isaís y Raquel Ojeda (coords) (2016), Sahara Occidental, 40 años después, Los libros de la catarata, Madrid.

Barona Castañeda, Claudia (2005), Los hijos de la nube: El Sahara Español desde 1958 hasta la debacle, Editorial Cuadernos de Langre, Madrid, España.

Caballero Mercadillo, Roberto E y Ahmed Mulay Ali (coord.) (2004). El otro en la arena. 20 miradas y un parpadeo al Sahara Occidental, Editorial Gedisa, Cuidad de México.

Cembrero, Ignacio (2009), "El estadounidense Christopher Ross, nuevo mediador del conflicto del Sahara", El país, España. Ver: www. internacional.el país.com, Consultado 9 de diciembre de 2016.

Cobo Fuentes, Ignacio y Fernando M. Mariño (2006), "El conflicto del Sahara occidental”, en Conflictos Internacionales Contemporáneos, núm. 4, Instituto de Estudios Internacionales y Europeos.

Confidencial Saharahui (2016), "El Ejército saharaui se hace con el control total de El Guerguerat y reabre la frontera con Mauritania”, en Confidencial Saharahui. Ver: www.confidencialsaharaui.com. Consultado el 13 de enero de 2017.

Cooper, Robert (2003), The Breaking of Nations. Order and chaos in the Twenty-First Century, London, Atlantic Books.

Etzioni, Amitai (2001), “On ending nationalism”, en IPG No. 2

Griffits, Martin, (2003), "Self-Determination, International Society and World Order", en Maquarie Law Journal, 29.

Dahbour, Omar (2003) Illusion of the Peoples: A Critique of National Selfdetermination, Rowman \& Littlefield.

(2006), "Advocating Sovereignty in an Age of Globalization," Journal of Social Philosophy.

(2007) "Hegemony and Rights: On the Liberal Justification for Empire," in Dawson/Schueller (eds.), Exceptional State: Contemporary U.S. Culture and the New Imperialism, Duke.

(2009) "Nationalism, Self-Determination, and Secession," in Patrick Hayden (ed.), Ashgate Companion to Ethics and International Relations.

(2012) "National Rights, Minority Rights, and Ethnic Cleansing," in Grace Cheng (ed.), Nationalism and Human Rights, Palgrave Macmillan. (2013) Self-Determination without Nationalism: A Theory of Postnational Sovereignty, Temple, Temple University Press. 
Del Pino, Domingo (1990), Marruecos entre la tradición y el modernismo, Universidad de Granada. España.

Diego Aguirre, José Ramón (1988), La Historia del Sahara Español. La verdad de una traición, Madrid, Kaydeda Ediciones.

(1991), Guerra en el Sahara, Ediciones Istmo, Madrid, España.

(1991), "La verdad sobre la entrega del Sahara", en: Historia 16, no 177, España.

EFE (2017), "La RASD (República Árabe Saharaui Democrática) daría la bienvenida a Marruecos si cumple con las normas de la UA". Agencia EFE. Consultado 26 de enero de 2017.

EFE (2017), "El Presidente Saharaui se reúne con el Secretario General de la ONU en New York", Ver: www.elconfidencialsaharaui.com. Consultado 18 de marzo de 2017.

Fernández Vera, Alberto (1979), Historia en las arenas, Editorial de Ciencias Sociales, La Habana, Cuba.

Francisco Peregil (2017), "El regreso de Marruecos a la Unión Africana abre una nueva era en el conflicto del Sahara", El País.

Garduño Castro, Moisés (2014), "La eterna importancia de los recursos naturales del Sahara occidental", en: Caballero Mercadillo, Roberto E y Ahmed Mulay Ali (coord.). El otro en la arena. 20 miradas y un parpadeo al Sahara Occidental, Editorial Gedisa, Cuidad de México.

González Tule, Luis A (2014), “Ocupación del Sahara Occidental: un conflicto pendiente y una sociedad en espera", en: Caballero Mercadillo, Roberto E y Ahmed Mulay Ali (coord.). El otro en la arena. 20 miradas y un parpadeo al Sahara Occidental, Editorial Gedisa, Cuidad de México.

Held, By David (2010) Cosmopolitanism: Ideals and Realities, Cambridge, UK, Polity Press.

Hernández Rangel, Fátima (2014), “La importancia geopolítica del Sahara Occidental en el conflicto con Marruecos", en: Caballero Mercadillo, Roberto E y Ahmed Mulay Ali (coord.). El otro en la arena. 20 miradas y un parpadeo al Sahara Occidental, Editorial Gedisa, Cuidad de México.

Kymlicka, Will (2004), "Universal Minority Rights? The Prospects for Consensus", en M. Yasutomo, I. Fumihiko and S. Tetsu (editores), Universal Minority Rights, A Transnational Approach, Franz Steiner Verlag: Stuttgart, pp. 13-57

Martínez Lillo, Pedro, Silvia Arias Careaga, Carlos Tanarro Alonso y Julia Weingartner (coords) (2009), Universidad y Sahara Occidental. Reflexiones para la solución de un conflicto, Cuadernos Solidarios, núm. 6, Universidad Autónoma de Madrid, España. 
Mohsen-Finan, khadija (2016), "Indigación de Marreucos contra Ban Ki-moon: ¿es el Sahara occidental un territorio ocupado?”, en Real Instituto Elcano, España. Ver: www. http://www.realinstitutoelcano.org, Consultado el 13 de enero de 2017.

Mora Tebas, Juan Alberto (2015), "Nueva resolución Consejo de Seguridad sobre Sahara Occidental: Un cuadragésimo aniversario ¿sin cambios?”, Instituto Español de Estudios Estratégicos, España.

(2016), "Un Consejo de Seguridad dividido adopta, sin consenso, una nueva resolución sobre el Sahara Occidental”, Instituto Español de Estudios Estratégicos, España.

NNUU (2003), "Peace Plan for Self-Determination of the People of Western Sahara".

Ohmae, Kenichi (1995), The End of the Nation-State: the Rise of Regional Economies. New York, Simon and Schuster Inc.

Ramón Criado (1977), Sahara. Pasión y muerte de un sueño colonial, París, Ruedo Ibérico.

Riquelme Cortado, Rosa (2013). "Marruecos frente a la (des) colonización del Sahara Occidental", en Anuario Mexicano de Derecho Internacional, vol 13, México.

Tan, Kok-Chor (2006) "Liberalism and Cultural Diversity: Some Challenges", en Tinnevelt, Ronald \& Verschraegen, Gert (Editors) Between Cosmopolitan Ideals and State Sovereignty. Studies in Global Justice, New York, Palgrave MacMillan, pp. 77-88.

Vidal, Lurdes (2003), "El Plan Baker: propuesta para solucionar el conflicto más antiguo del Magreb", en Afkar/Ideas.

Zolo, Danilo (1997), Cosmopolis, Cambridge Mass., Polity Press \& Blackwell Publishers, Ltd.

Zoubir, Yahia (2009). "The United States and Maghreb-Sahel Security", en International Affairs, $\mathrm{n}^{\circ}$ 85:5. 
